\title{
Entrevista com Marlos Cholodovskis Machado
}

\author{
Heslley Machado Silva ${ }^{1}$
}

${ }^{1}$ Centro Universitário de Formiga (UNIFOR-MG)

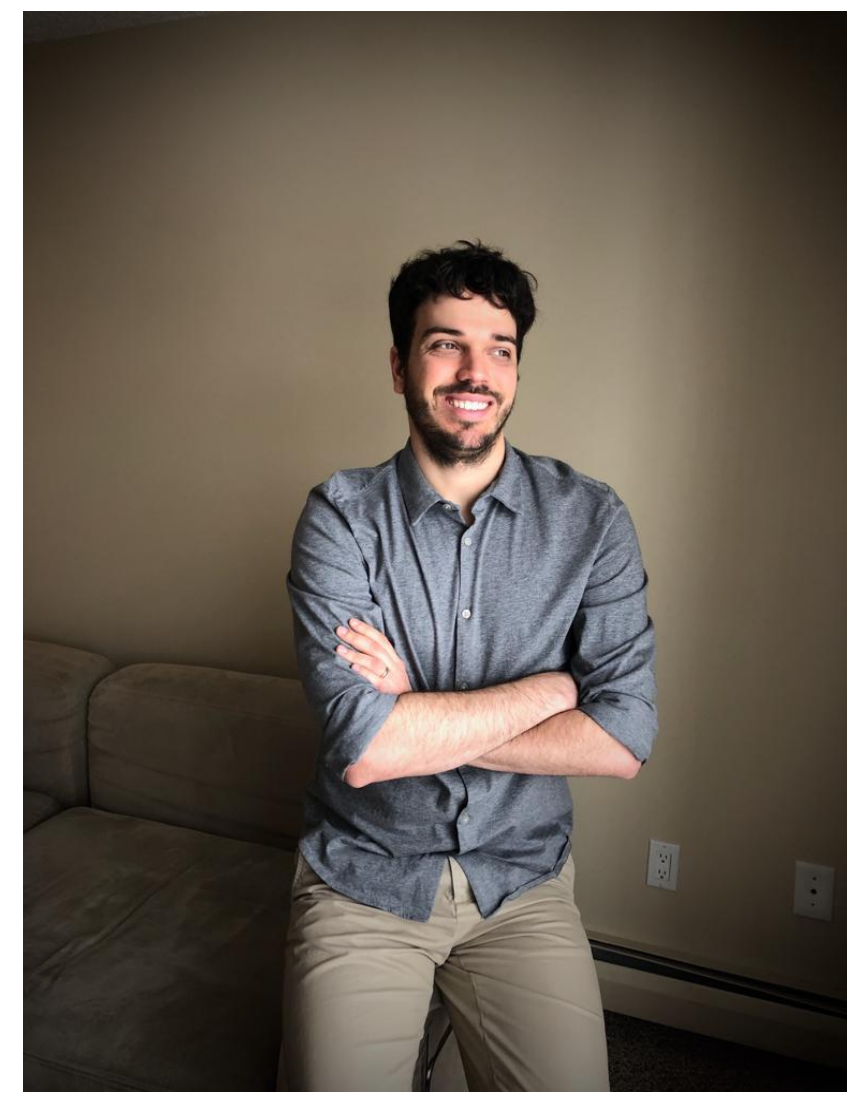

O entrevistado dessa edição da revista Conexão Ciência é o Dr. Marlos Cholodovskis Machado, bacharel e mestre em ciência da computação pela Universidade Federal de Minas Gerais, e doutor em ciência da computação pela University of Alberta, Canadá. Marlos tem recebido diversos reconhecimentos ao longo de sua carreira, incluindo prêmios como melhor aluno da sua graduaçāo, melhor trabalho em andamento do seu mestrado e, atualmente, é um dos indicados para o prêmio de melhor tese doutorado do departamento de ciência da computaçāo da University of Alberta. Ele publica com frequência nas principais conferências $e$ periódicos da área e durante seu doutorado fez estágios na Microsoft Research, IBM Research, e DeepMind. É pesquisador no Google Brain, em Montréal. Os seus interesses de pesquisa residem, de forma geral, em inteligência artificial, mais especificamente em aprendizado de máquina $e$ aprendizado por reforço. 
1. Dr. Marlos, explique-nos, por favor, de que se trata sua principal área de interesse e de trabalho. A maioria de nós conhece um pouco de Inteligência Artificial, mas o que é "aprendizado por reforço"?

Em computação, quando queremos que o computador faça alguma coisa, nós programamos esse computador para fazer essa coisa. Basicamente, damos ao computador o passo a passo de como fazer algo, como se fosse uma receita de um bolo. O problema é que existem comportamentos que, às vezes, queremos que o computador tenha que não sabemos como dar o passo a passo. Por exemplo, qual o passo a passo, exato, para falar? Alguém consegue descrever, exatamente, como os mexer as cordas vocais para produzir cada som? Aprendizado por reforço é a ideia de que o computador aprende por tentativa e erro. Ao invés de falar como você quer que ele faça algo (as regras), você deixa o computador tentar várias coisas, e quando ele faz algo certo você só envia o sinal de "parabéns!" ao computador. O computador gosta de receber "parabéns", então ele começa a aprender quais ações que ele fez e que deve repetir para ganhar mais "parabéns". Ou seja, no exemplo de aprender a falar, a princípio, o computador emitirá sons aleatórios, mas quando algo soar como uma palavra de verdade você dá "parabéns" e o encoraja. Com o tempo, assim como crianças, o computador pode "aprender a falar". Não é muito diferente de treinar um cachorro com pequenas recompensas, quando ele faz algo certo.

2. De Formiga para o cargo de cientista pesquisador de um laboratório do Google no Canadá, uma trajetória absolutamente bemsucedida, um emprego sonhado para muitos com interesse no mundo da tecnologia. Conte-nos um pouco desse caminho e qual foi sua maior dificuldade?

Eu sou de Formiga e vivi em Formiga até os 17 anos, quando terminei o ensino médio e prestei vestibular para ciência da computação na UFMG. Eu passei e me mudei para Belo Horizonte. Lá acabei me envolvendo com pesquisa por meio de uma bolsa de iniciação científica e, desde então, continuei fazendo isso. Continuando com esse interesse, fiz mestrado na UFMG, enquanto trabalhava em período parcial, e durante o mestrado decidi tentar o processo de seleção para fazer o doutorado fora. Acabei aceitando a oferta da University of Alberta, e eu e minha esposa (me casei durante o mestrado) nos mudamos para o Canadá, ambos para fazer seus respectivos doutorados. Seis anos depois, quando defendi o doutorado, depois de ter feito estágios nos laboratórios de pesquisa da Microsoft, IBM, e DeepMind, eu decidi aceitar a oferta do laboratório de pesquisa do Google para ser um pesquisador deles. Certamente existiram diversos desafios nesse caminho. No Brasil, acho que um grande desafio é o reconhecimento. No geral, estudar não é muito valorizado, quem dirá fazer pesquisa. Isso se reflete no valor das bolsas, em como as pessoas veem o que você faz, etc. No exterior, um grande problema é representatividade. Quando se vê esse tipo de emprego (ou doutorado), ele geralmente não é ocupado por um brasileiro que veio do interior. Então você acaba tendo que trabalhar muito para mostrar que você pode chegar lá. Um exemplo concreto disso é que a larga maioria dos pesquisadores internacionais, na minha área, não conhece uma única universidade brasileira. Nesse contexto, como fazer com que te aceitem para um doutorado, por exemplo?

\section{Uma dica fundamental àqueles} leitores que querem seguir os seus passos.

Estudar, estudar, estudar. Estudar na escola, estudar na faculdade, estudar inglês, estudar. Além disso, sonhar. Como dizem, "o não você já tem”, então ser ambicioso e tentar grandes oportunidades é essencial.

4. Tenho notícia de que sua tese está sendo cogitada para ser premiada como a melhor do seu departamento de pesquisa, que é um dos mais conceituados do mundo na sua área. Você tem outras premiações na sua vida acadêmica, mas especificamente sobre essa, a que você atribui essa deferência? $E$, novamente, dê uma dica para os futuros pesquisadores, nossos leitores, poderem produzir um texto com tamanho destaque.

Sendo muito sincero, uma nomeação dessas, em meio a tantos colegas brilhantes, envolve muita sorte. Sorte de você ter tido a ideia certa, de ter funcionado, e por aí vai. Mas se eu tivesse que pensar no que acho que fiz certo, acho que ambição. A todo lugar que fui, eu fui com o objetivo de ser o melhor. Nunca me acomodei e sempre corri atrás de oportunidades melhores e diferentes. No meu doutorado, por exemplo, isso se refletiu nos estágios que fiz. Acho que nessa hora ser brasileiro ajuda porque, infelizmente, estamos acostumados a ter que trabalhar duro para conseguir as coisas, já que nada vem fácil. Acho que fui para o doutorado sabendo que essa seria a oportunidade da minha vida, e eu não quis arriscar ter que esperar uma segunda chance.

5. Muitos estudantes de graduação brasileiros e, mesmo pesquisadores e professores, almejam viver uma experiência no exterior como a sua. Exponha-nos, sucintamente, as maiores vantagens e dificuldades dessa vivência.

Acho que a maior vantagem é o nível de excelência ao qual você é exposto. Aqui não existe o conceito de fazer "pesquisa de ponta", pesquisa de ponta aqui é o que eles chamam de pesquisa. Ou seja, você está entre os melhores do mundo. A grande desvantagem, claro, é a distância da família e do Brasil. Você passa a ver seus pais uma vez por ano, no máximo, você passa a conversar em uma língua 
diferente do Português grande parte do tempo, para de comer as comidas que crescemos comendo, e por aí vai. No início é tudo novo e legal, com o tempo a saudade bate.

6. Além do tema da Inteligência Artificial, quais os temas que você considera que serão "quentes" na área da tecnologia? O que você sugeriria para jovens estudantes e pesquisadores brasileiros?

Eu, sinceramente, acho que computação, no geral, é um tema muito "quente". Eu frequentemente falo para meu pai, que dá aula para alunos de ensino médio, para que ele abra os olhos dos alunos para o quão promissor computação é. É muito difícil que alguém erre indo para a área de computação porque cada vez mais estamos mais conectados e as coisas são mais automatizadas. Dentro de computação, mineração de dados (ou a buzzword "big data"), segurança da informação, privacidade, robótica, são todas áreas muito promissoras.

7. $\quad$ E dentro da Inteligência Artificial? Quais as áreas ou tópicos que você percebe como mais promissores?

O interesse em inteligência artificial está explodindo no mundo. Dentro dessa explosão, algumas das áreas que mais crescem são redes neurais (ou deep learning), aprendizado por reforço, e interpretabilidade de sistemas de inteligência artificial.

8. Quais as características mais desejáveis (e as menos desejáveis) que você consideraria para alguém que tem interesse em trabalhar com você no laboratório do Google? Ou para ser seu orientando de mestrado e doutorado?

Existem várias coisas que procuro em um aluno. É absolutamente essencial que essa pessoa seja fácil de lidar e que ela saiba trabalhar em equipe. A idéia do gênio temperamental que todo mundo simplesmente tolera não existe. Além disso, eu me identifico muito com pessoas ambiciosas que trabalham muito e são pró-ativas. Em termos mais técnicos, eu sempre tento avaliar a base matemática e a experiência, em termos de pesquisa, das pessoas que querem trabalhar comigo.

9. É humilhante diante do universo de desemprego brasileiro, mas tenho conhecimento, de que você teve que escolher entre propostas muito interessantes de emprego em várias partes do mundo quando concluiu o doutorado. Primeiro, a que você atribui esse privilégio (sem modéstia)? Segundo, se não for problema contar, que propostas foram essas? $\mathrm{E}$, por fim, por que a decisão pelo Google e a continuidade no Canadá?

Eu dei sorte com o fato do interesse em aprendizado por reforço ter explodido quando estava terminando meu doutorado. Além disso, a ambição, o fato de eu ter feito estágio em diferentes laboratórios do mundo, e o fato de ter tido um doutorado tão bemsucedido foram essenciais para isso. Ao final do meu doutorado eu tive propostas de laboratórios de pesquisa do Google, da Microsoft, e da DeepMind, para cidades como Londres, Nova York, e Montréal. Escolher foi uma das decisões mais difíceis da minha vida, porque eu genuinamente me senti honrado de receber essas ofertas. Minha esposa e eu gostamos muito do Canadá, acabamos de ter uma filha, e pensamos que ficar no Canadá, nesse momento, era a coisa certa a se fazer. Nós gostamos dos valores do país, da maior igualdade social, da segurança, educação, e decidimos que a princípio é onde queremos tentar criar nossa filha.

10. Finalmente, dê uma mensagem de incentivo para os nossos leitores, sobre o valor do estudo e do esforço de uma forma geral, em um mundo em que as redes sociais são onipresentes, infelizmente, muitas vezes, ocupando um tempo e um foco precioso das mentes dos estudantes com futilidades e discussões de ódio.

$\mathrm{Eu}$, sinceramente, poderia encher páginas falando da importância do estudo. Poucas coisas têm um poder tão transformador quanto o estudo e a informação. Ao mesmo tempo, eu reconheço que não é fácil, não é necessariamente a coisa mais divertida do mundo e, certamente, não é tão reconhecido e incentivado. O que posso falar é que, na minha cabeça, estudar certamente não é o único caminho para o sucesso, mas é certamente o mais seguro (ou garantido). Nunca vivemos em uma era tão conectada, e isso tem seus benefícios e malefícios. Acho que o importante é as pessoas tentarem tirar o que há de melhor do que existe hoje. Hoje, se alguém quiser aprender algo, provavelmente, existe um vídeo do YouTube ensinando. Se alguém quiser acompanhar uma pessoa (por exemplo, um cientista), essa pessoa provavelmente está no Twitter. Isso nunca aconteceu e é fantástico. Mas claro, é importante estar atento para os perigos dessa superconectividade. Duas coisas essenciais são: (1) estar sempre aberto para diferentes pontos de vista, já que é tão fácil se isolar em uma bolha de pessoas que pensam igual a você; e (2) checar fatos, já que hoje qualquer pessoa gera conteúdo e, muitas vezes, isso nada mais é do que fake news. 